\title{
3D Technologies for Museums in Berlin
}

\author{
Hartmut Schwandt \\ Technische Universitaet Berlin \\ Fakultaet II, Institut fuer Mathematik \\ 3D Labor \\ Sekr. MA 6-4, Strasse des 17. Juni 135 \\ 10623 Berlin, Germany \\ schwandt@math.tu-berlin.de
}

\author{
Joachim Weinhold \\ Technische Universitaet Berlin \\ Fakultaet II, Institut fuer Mathematik \\ 3D Labor \\ Sekr. MA 6-4, Strasse des 17. Juni 135 \\ 10623 Berlin, Germany \\ weinhold@math.tu-berlin.de
}

\begin{abstract}
The 3D Laboratory at the TU Berlin cooperates with several museums of regional and national relevance by developing 3D applications and by transferring 3D technologies with the intention to support both the scientific work of museums (3D digitalisation, restoration, 3D replicas) and the improvement of the public presentation of the museums.
\end{abstract}

3D printing. 3D scanning. Museums. Rapid prototyping for scientific work in museums. Rapid manufacturing for exhibits.

\section{INTRODUCTION}

The 3D Laboratory at the Institute of Mathematics at the TU Berlin was founded in 2004 initially with the intention to support the mathematical visualisation group of the institute by operating an immersive stereo projection system. For the first time in 2005 the equipment was extended significantly by $3 \mathrm{D}$ printing and $3 \mathrm{D}$ scanning facilities using grants of the EFRE (European Fund for Regional Development). The 3D Laboratory became an independent institution inside the institute with a broad range of applications and which cooperates with numerous institutions. The current equipment includes four plaster printers from several generations, a fused deposition modelling (FDM) printer and a selective laser sintering system for polyamide, a 3D scanner and a static and a mobile stereoscopic immersive projection system as well as a comprehensive IT infrastructure.

Currently the team consists of its professor, two fulltime and two temporary scientific assistants and seven student assistants. From the beginning the 3D Lab has pursued a strictly interdisciplinary approach as its staff originates from various disciplines - currently from architecture and fine arts as well as from mathematics. As a consequence it has been possible to cooperate with institutions that are not usually in the focus of a mathematical institute but which are involved in the dynamics of the rise of 3D technologies and the development of relevant uses and applications.

Besides the "typical" scientific, technical and industrial applications, the 3D Lab as involved in teaching especially with respect to the promotion of 3D technologies and cooperates, for example, also with artists and designers or architects: The fact that more and more students from the architectural departments of the TU Berlin and the nearby University of the Arts Berlin build their architectural models for their diploma or master thesis by using rapid prototyping at the 3D Lab can be understood as a turn to cultural issues. The cooperation with museums constitutes a rapidly growing activity field of the 3D Lab. Starting with the Gipsformerei (Art Manufacture) and the Egyptian Museum as institutions of the Staatliche Museen Berlin we noticed an obvious and increasing need for 3D applications. The main issues in this context are the 3D digitalisation and therefore digital conservation of cultural heritage, but as well support of restoration or presentation of exhibits for different purposes.

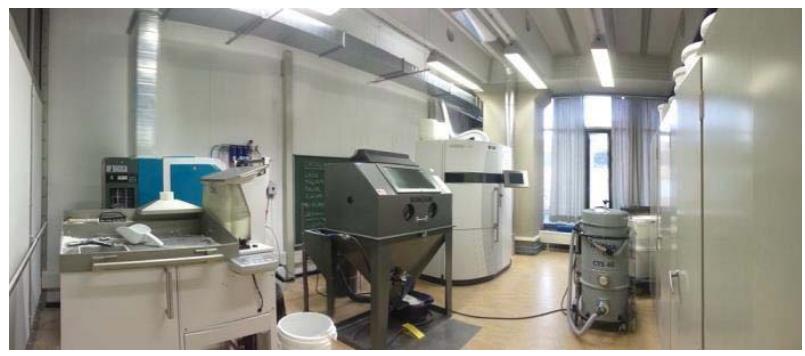

Figure 1: SLS (selective laser sintering) machine with peripheral equipment 


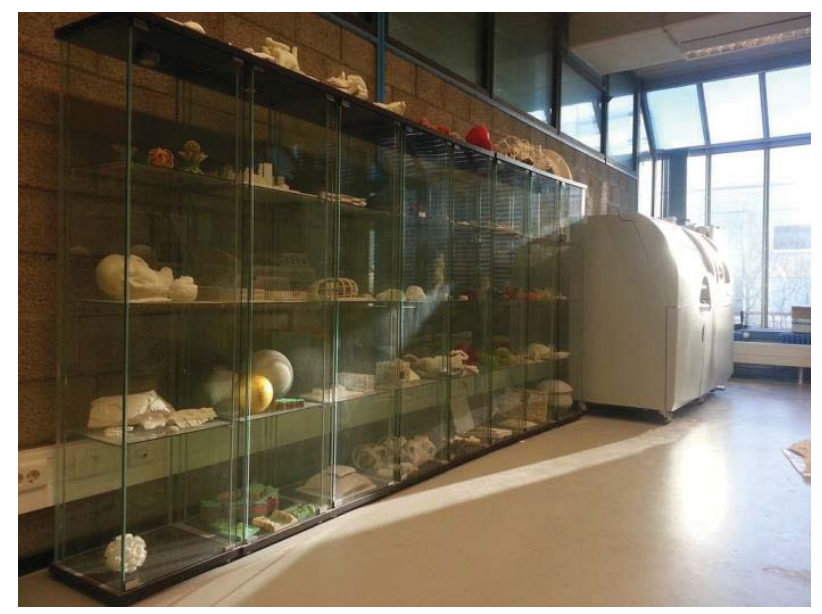

Figure 2: Plaster printers and show cases

\section{3D TECHNOLOGIES FOR MUSEUMS - PROJECT MOTIVATION}

The use of 3D technologies on a professional level is still bound to costly equipment and material. Most museums cannot buy a 3D scanner or 3D printer. This equipment also needs skilled staff specialised in using 3D technology. These costs are too high to allow for experiments. Based on successful smaller pilot projects the idea of knowledge transfer of 3D technologies to smaller museums at Berlin was born. This includes the definition and satisfaction of the individual needs of this museums as well as the determination of limits that still exist. The aim of this project is not only to support smaller museums with technical assistance and knowledge transfer, but also to give the partner institutions an overview on usage and perspectives of these technologies in their scientific work and public exhibitions. As the selected museums collect a very broad variety of objects with different characteristics and as they have different aims in the use of and the presentation with 3D technologies the project is as well dedicated to demonstrate the bandwidth of possibilities. This report on a work in progress shows some first results of the cooperation project granted by EFRE and illustrates some other activities of the 3D Lab in the context of museum applications.

\section{STEP BY STEP - PRELIMINARY PROJECTS}

Former smaller projects have led to the current project "3D technology for Berlin Museums". The first contacts with museums resulted from specific problems related to the scientific work of the Egyptian Museum of the Staatliche Museen zu Berlin. These problems could not be solved with standard methods in that application field. We outline two examples illustrating typical questions museums are faced with in their daily work.

\subsection{Head of Queen Tiye and crown - Art Manu- facture and Egyptian Museum of the Staatliche Museen zu Berlin - Stiftung Preussischer Kulturbesitz}

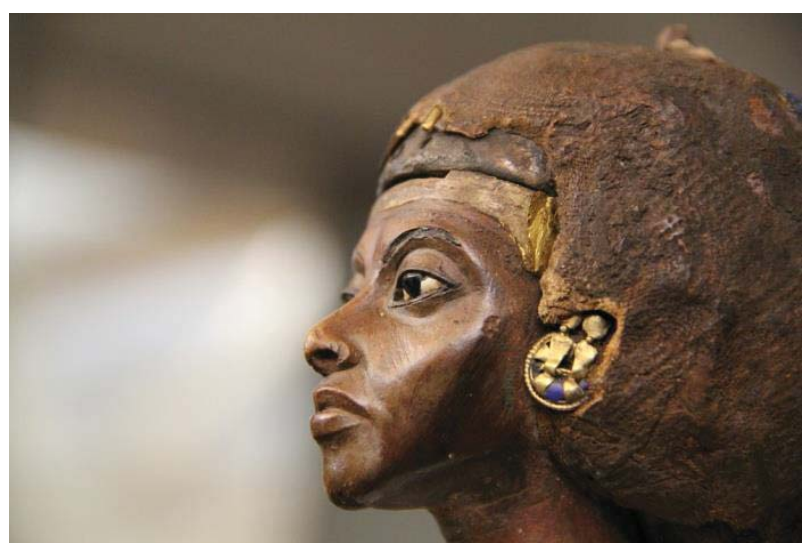

Figure 3: Crownless head sculpture of queen Tiye

In contrast to former times, the crown of this little sculpture of the Egyptian queen Tiye should not be moulded as this might damage it. The head was moulded at the beginning of the sixties of the 20th century by the Gipsformerei by gelatine casting. Thus, a replica of the head exists, but none of the crown, which had been added to the sculpture later. In cooperation with the Egyptian Museum and the Gipsformerei the 3D Lab produced a structured light scan of the crown and reproduced it as 3D print which can be moulded by traditional means. Meanwhile the Gipsformerei produces and distributes replicas of the sculpture of Tiye with the crown. The application of 3D scanning and 3D printing has yielded two results. Keeping in mind the lost original, a handmade plaster model was the only remaining copy of that sculpture. Plaster models degenerate and new moulds could not been made from original. 3D scanning offers the possibility to get indestructible 3D data allowing for fabricating new moulds or real, reproducible copies using a 3D printer.

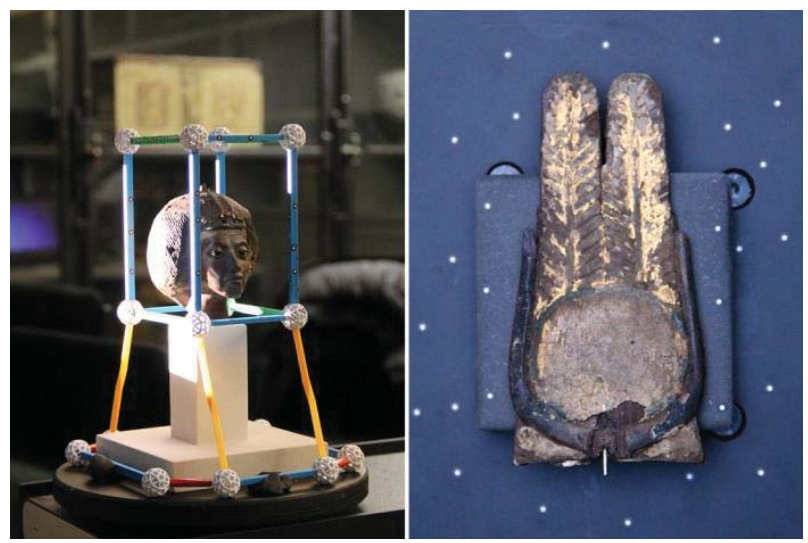

Figure 4: 3D scan setups for the head and the crown 
The original wooden crown is so sensitive that it is not possible to produce a mould from the original. A $3 \mathrm{D}$ scan yields the necessary data without touching the original. 3D printing has even permitted to produce a "complete" model with head and crown. This illustrates the possibilities of 3D technologies to create very precise 3D digital data which preserve an objet at least digitally even if the original is lost. In addition, 3D printing allows for producing real "touchable" copies in any desired number at any moment.
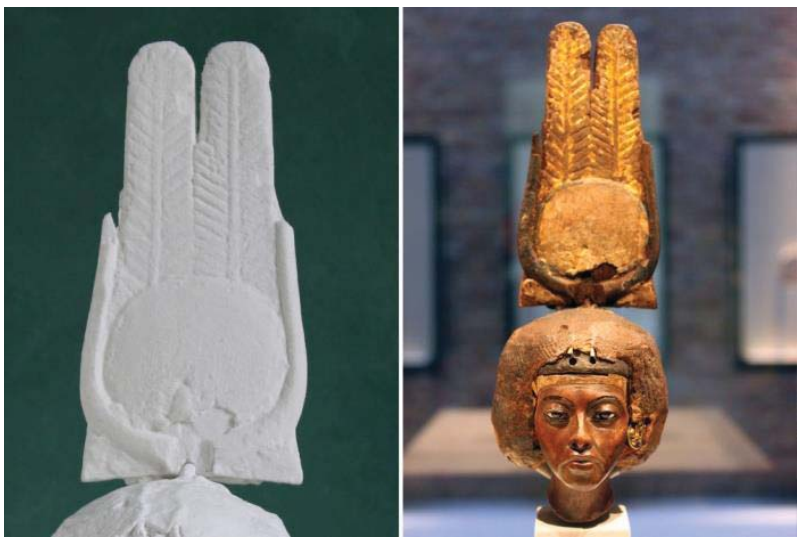

Figure 5: 3D printed, later painted and attached crown

\subsection{Bust of Pharaoh Akhenaten - Egyptian Museum of the Staatliche Museen zu Berlin}

In the exhibition "Im Licht von Amarna" ("in the light of Amarna") the bust of Pharaoh Akhenaten has been presented for the first time after its last restoration. The 3D Lab was involved into this exhibition by a structured light scan and a 3D print in original size. The 3D printing had two main successfully fulfilled aims: The reproduction of the shape of the bust in the appearance of the first reconstruction after the discovery in order to present it in the exhibition and the support of the reconstruction of the missing mouth, which is lost.

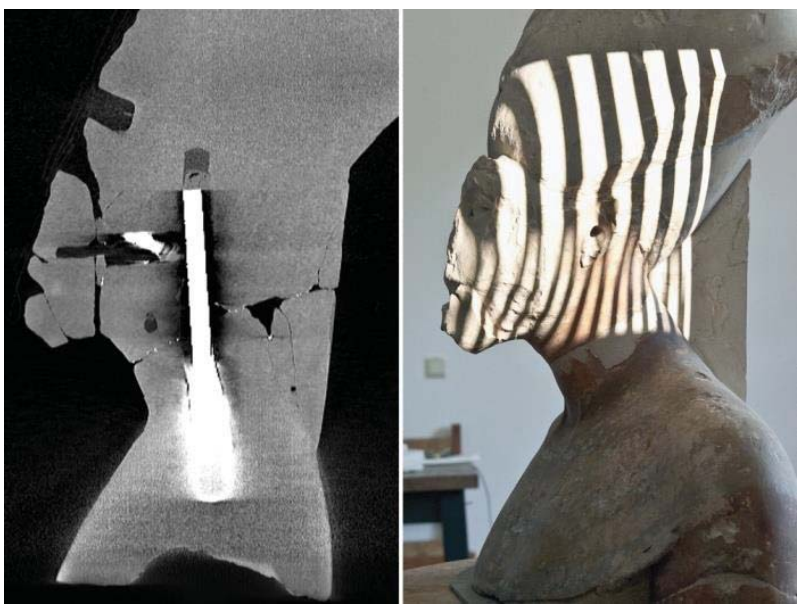

Figure 6: CAT scan image and surface scan process
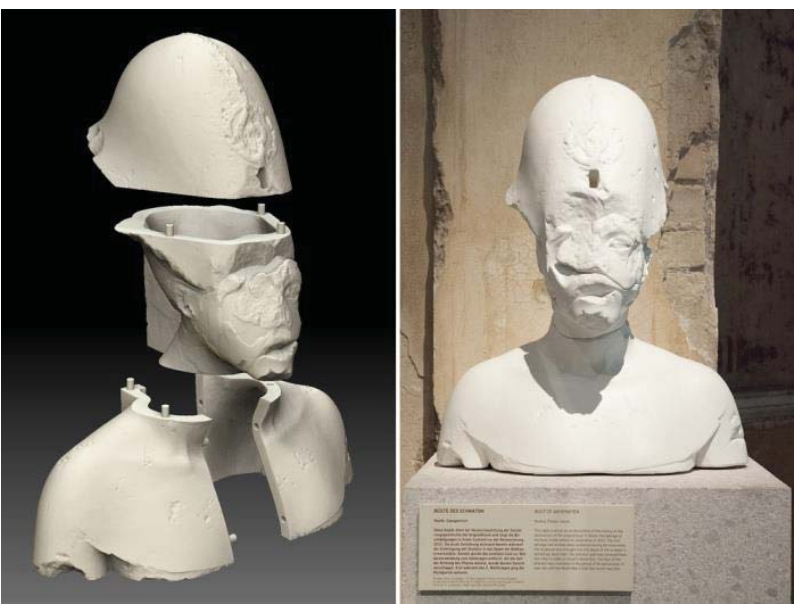

Figure 7: The bust before and after 3D printing

In a first step the bust was passed through a computer tomograph normally used for human patients at the Imaging Science Institute of the Charité, the university hospital at Berlin. The CT images enabled the Egyptian Museum to determine the current "internal" condition of the bust, which had been damaged and restored several times. This information has ben indispensible for further restoration work. The 3D Lab used the CT data together with the data from a 3D scan to produce a 3D model of original size. The model was first used by the conservator to plan and to test further restoration works before touching the original. In the exhibition, the temporarily restored original (the missing mouth was added), our 3D model of the unrestored original and another 3D print copy from the second bust of Akhenaten from the Louvre at Paris were shown. From the point of view of 3D technology, we tested for the first time the combination of CT data and 3D scan data. On the one hand, data form human CTs usually have an unsatisfactory image resolution due to the limited radiation intensity of these machines. This drawback can be remediated by the very precise surface data yielded by a $3 D$ scan. On the other hand, the 3D scan of complicated and detailed structures requires sometimes hundreds of measurements leading to hundreds of overlapping digital "2.5 D images" which have to be combined to a single digital 3D model. The combination of many overlapping image data sets yields to an inevitable, sometimes significant error propagation leading to shape deformations. The latter can, however, be drastically reduced by the more precise shape information from the CT data.

\section{CURRENT PROJECT - 3D TECHNOLOGY FOR MUSEUMS AT BERLIN}

Our current, larger project granted by EFRE consists of four subprojects with museums at Berlin. Each subproject is dedicated to a specific application of one of the cooperating museums where one 
or more 3D techniques of general interest are applied.

\subsection{Gipsformerei - Art Manufacture of the Staatliche Museen zu Berlin}

In this subproject it is mainly intended to produce 3D scans and 3D prints of sculptures from the large collection of plaster replicas of the Gipsformerei. In contrast to former projects with this partner the digitalisation of objects is more important than the solution of isolated problems. We plan a complete 3D digitalisation of a single group of sculptures in the collection of the Plaster Replica workshop: Sixteen sculptures of Greek legendary figures by Friedrich Tieck, originally sculpted for the tea room of the Berlin City Castle that is aimed to be reconstructed in the next years. The Gipsformerei aims to build a scaled model of the tea room for public exhibition. As the shape of these sculptures is in some details very complex, they yield a good example for a problem the 3D Lab is frequently faced with when sculptural objects had to be scanned: Structured light scanners cannot really reach every detail in complex shapes. Even by scanning objects with more than a thousand single scans it is sometimes impossible to depict every detail of a shape. Strong undercuts or holes have to be reconstructed in the post-processing of a 3D scan. As this problem can usually be neglected in the case of small replicas from large sculptures it is still an aim to reproduce a shape completely instead of using automatically generated or handmade reconstructions.
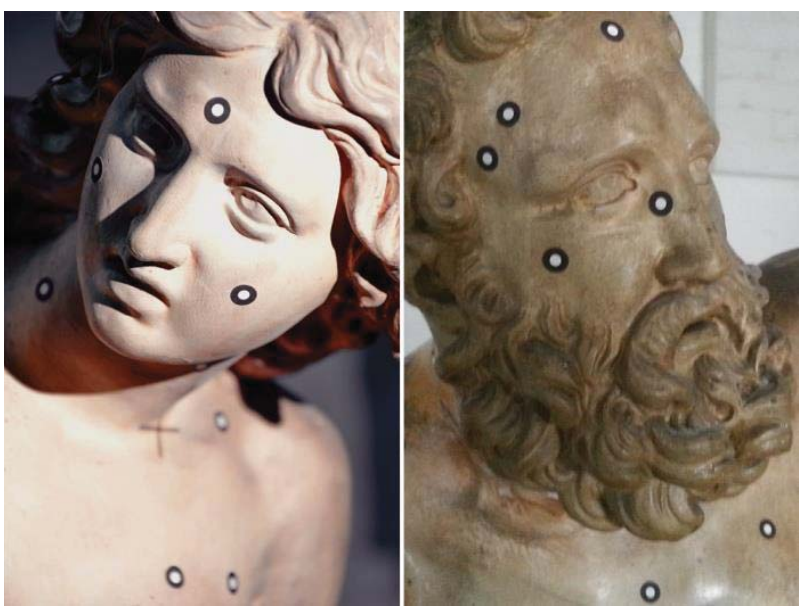

Figure 8: Cassandra and Hercules statues with reference points

As it is intended to build a scaled model of the complete tea room for an exhibition, the quality of the plaster replicas of sculptures must be rather high. While the surface details can be reproduced in high precision by careful 3D scanning, additional post processing and a careful 3D print, it remains the problem that the specific plaster and the necessary infiltration with epoxy resin yield colours which are not appropriate for all purposes. We are, therefore, adding supplementary colour pigments to the plaster. In the present case, the addition of titanium white pigments resulted in a rather pure white.

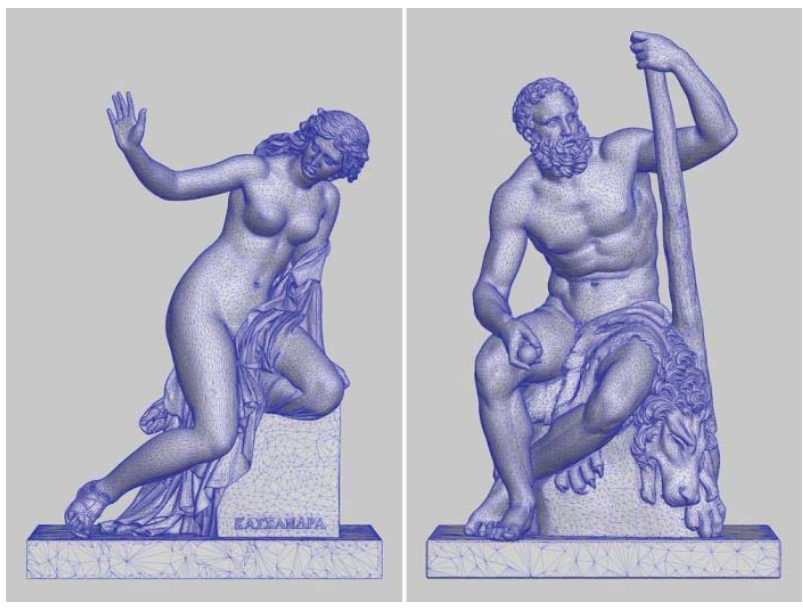

Figure 9: 3D files of the Cassandra and Hercules statues in a tessellated view

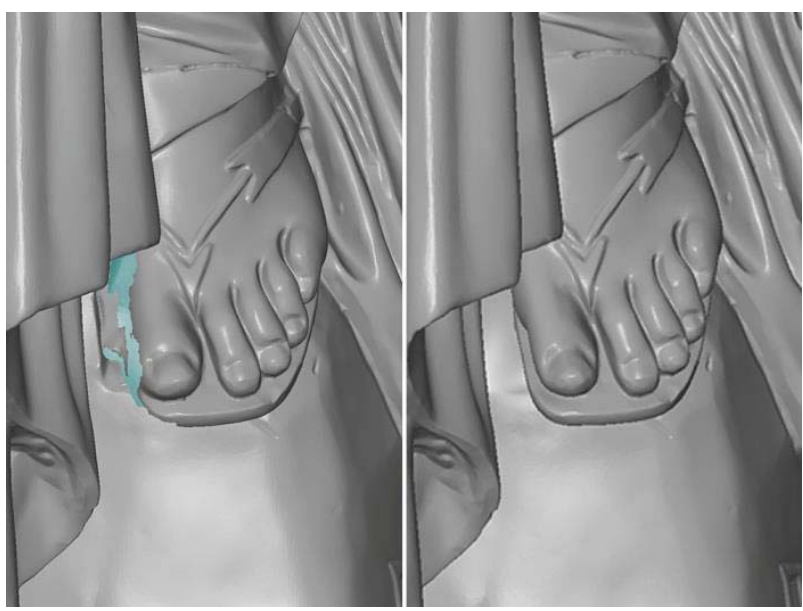

Figure 10: Reconstructed part of a Persephone statue which cannot be scanned correctly

\subsection{Stiftung Stadtmuseum Berlin}

The main issue in this cooperation is the $3 \mathrm{D}$ scan of architectural models of the cityscape of Berlin from different centuries. The models themselves date from the 20th or even $19^{\text {th }}$ centuries, carved in wood and cannot be disassembled. The detailed geometry of the models, depicting houses, churches and little yards on a surface of several square metres is causing problems in the attempt to grasp the complete information as mentioned before: In principle, a high resolution from a distances up to several metres is required. It is, therefore, necessary to experiment with several scanning and reconstruction techniques.

After scanning the architectural models, the post processed data will be the basis for their digital reconstruction. A 3D scan would provide accurate but too large data files for the purpose of the intended 
use. The purpose of this digitalisation consists in a virtual interactive presentation for a walk through the space and time of the cityscape of Berlin.

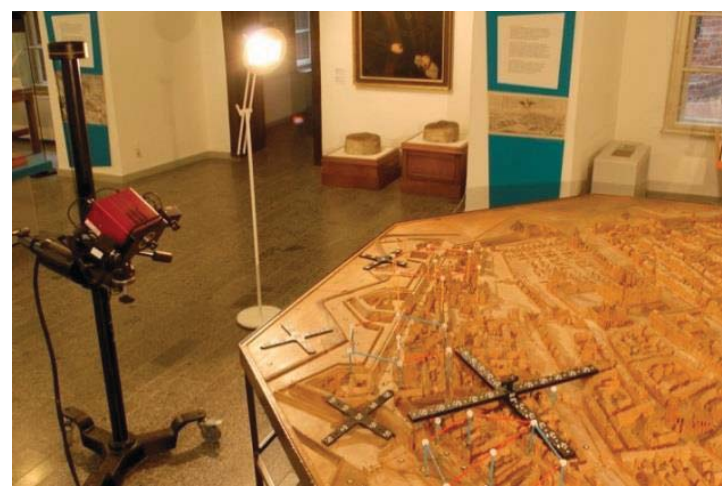

Figure 11: 3D scan setup for a wooden model of Berlin in 1680

\subsection{Museum Neukölln}

The Museum Neukölln is a regional museum focusing on the history of the Berlin quarter Neukölln. One of the central parts of its collection are exhibits from various times represented in combination with the history that they represent. The large variety of shapes and materials is reflected yield one of the characteristics of this cooperation, which has currently reached the phase of producing 3D scans with two different technologies. As in most museums the exhibits are shown in glass cabinets and are not to be touched by the visitors. After the postprocessing of the 3D scans some exhibits will be reproduced as 3D printed scaled models which permit a better access for visitors with visual handicaps. In addition, models which can be touched improve the interest for a visit in a museum pupils. The presentation of touchable replicas of the exhibits in different scales is intended to make small details of objects better accessible to blind people. The usability and acceptance of this application will be evaluated later in 2014 in workshops.

Among the exhibits to be scanned, there are an urn from the Bronze Age, a seal from a letter, a taxidermied bird (a large bustard) as well as sculptures, an amulet made by a Syrian prisoner and the lower jaw of a young mammoth. Due to some restrictions in the allowed handling of the objects two different technologies will be used. Besides the use of its own structured light scanning system the 3D Lab will continue its cooperation with the Leibniz Institute for Zoo und Wildlife Research at Berlin, which will produce CT scans of the urn and the lower jaw of the mammoth. Due to the surface and the fragility of the mammoth jaw it must not be turned upside down as needed in order to produce scans from all perspectives to get the whole shape. Additionally the surface is littered with little holes, which makes it improbable to generate a closed surface and in the follow a 3D printable file.
A more experimental scan will be the CT scan of a radio from the early 20th century. Scans like this one have the intention to demonstrate, what is possible and which quality of data is reachable. The generated data are intended to be used for different purposes, such as "fly-through-animations" or digital representation with haptic devices.

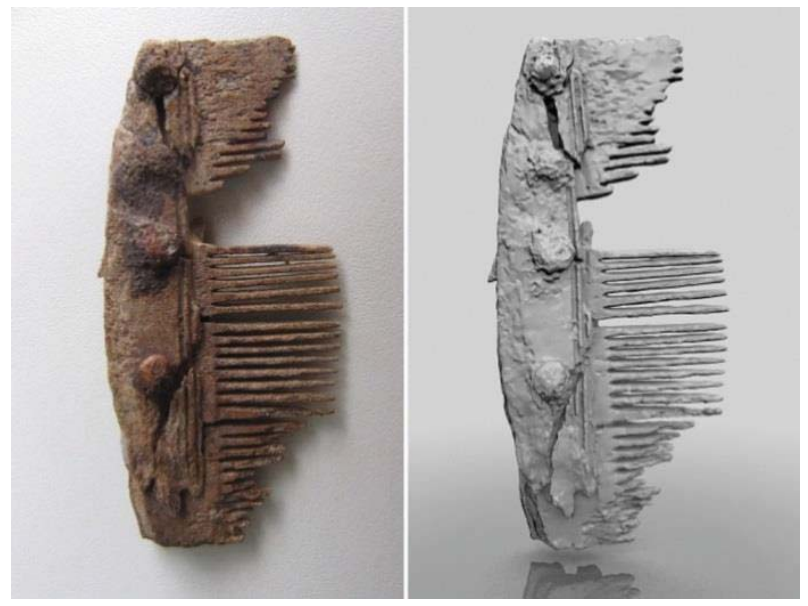

Figure 12: Bone comb from around 525-560 and its digitized counterpart

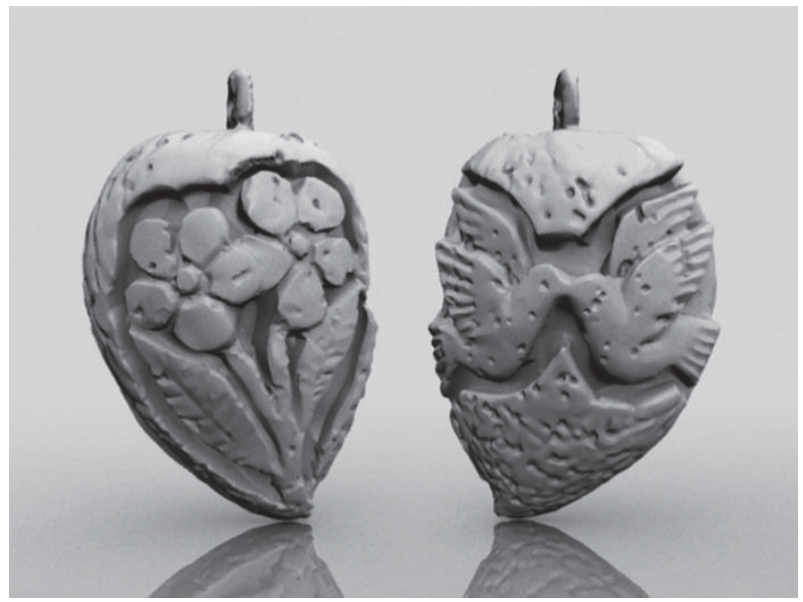

Figure 13: Carved peach seed amulet from around 1989



Figure 14: Comb and amulet as SLS prints in original size and plaster prints in a scale of 5:1 


\subsection{Spandau Citadel}

The main theme of this pilot project differs insofar from the others, as the results will be directly integrated into the exhibition "Berlin Enthuellt" ("Berlin Revealed") of the Spandau Citadel starting at the end of 2014. The part of this historical exhibition provided by the 3D Lab will be a virtual interactive representation of the so-called "great hall" that would have been a central building in the city "Germania" planned by Albert Speer and intended to be build instead of Berlin by the Nazi government.

Visualising the enormous size that this building would have had, is difficult as it is presumably beyond every ones imagination. Using a scaled model will give an impression of the relation to other buildings but cannot communicate the discomfort that would have been produced by this building. Installing an immersive and interactive stereo projection system would have been far beyond the budget. The Spandau Citadel, advised by the 3D Lab with respect to possible technical solutions, decided to integrate a tool into the exhibition that revives the representation of virtual realities by using head mounted displays of the current state of the art. The first available version of the "Oculus Rift" is in use at the 3D Lab since nearly one year and has been evaluated especially in relation to its acceptance by the audience. As the field of view of this device is much larger compared to earlier systems and the software, combined with a tracking system, is capable to provide a free view in all directions without latencies these HMDs provide the viewer with a highly immersive, interactive view into the virtual realities that are represented. In order to visualise the dimensions of the building of $290 \mathrm{~m}$ in height and $315 \mathrm{~m}$ edge length at the basis, the visitor will approach the simulated building in the virtual environment with two different velocities - at first similar to a car starting from a larger virtual distance and later like a pedestrian on the last $500 \mathrm{~m}$. The virtual environment is currently constructed in 3Dstudio max and will be completed by reconstructions using the original design drawings.

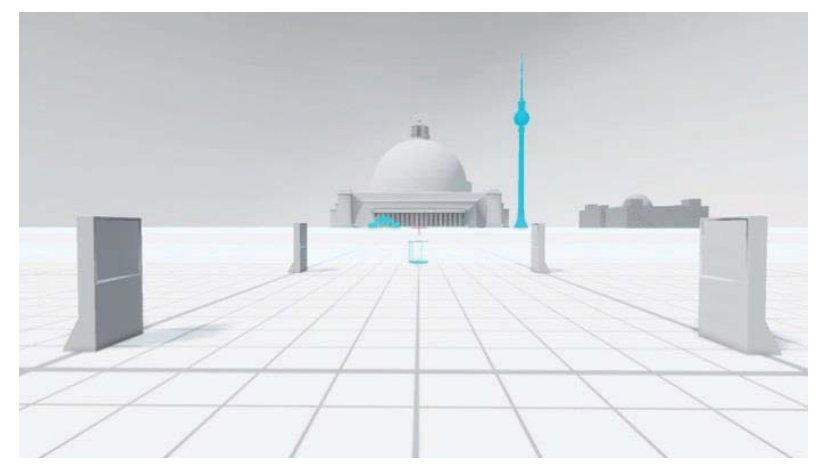

Figure 15: A simulated environment including the never built Great Hall of Germania and comparative buildings

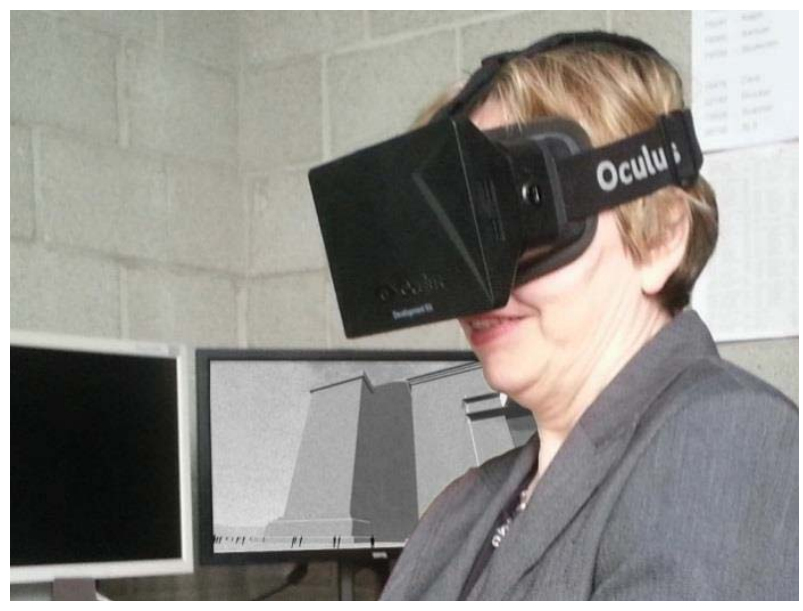

Figure 16: Using the "Oculus Rift"

\section{RELATED ACTIVITIES}

Due to the increasing interest in 3D printing the 3D Lab has been consulted by contemporary artists as well as by museums with collections in different areas of interest. In the following we mention two examples of current projects in this context.

\subsection{Digital preparation of fossils}

In cooperation with the Natural History Museum Berlin and the Charité, the 3D Lab processed the CT data of a Plateosaur vertebra, which still remains enclosed in the rock that hosted it for millions of years. The cooperation led to a publication in the medical journal "Radiology" in 2013. The benefit for the Natural History Museum Berlin consists in the possibility to identify the rows with embedded fossils, as the labels were lost because of a bomb impact during the Second World War. The second main benefit was, that it was possible to get the shape of the vertebra as a digital and also as a real object in a very short time compared to a preparation in the traditional way. This application requires in particular a careful image processing, more precisely image segmentation, when "extracting" the vertebra virtually from the rock.

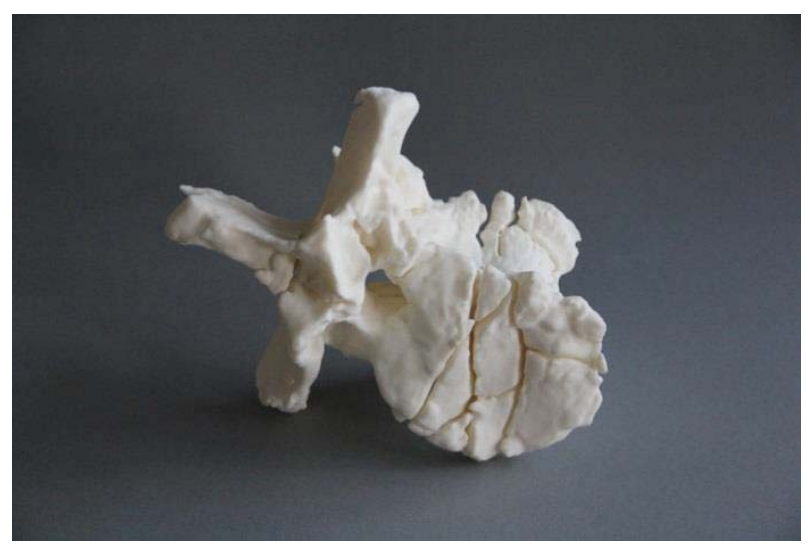

Figure 17: 3D print of a Plateosaur vertebra 


\subsection{Biface}

As the 3D Lab continues its experiments with possible uses of 3D technologies it realizes "in between" projects like this 3D print from a 3D scanned hand axe, bringing together one of the first tools of mankind with one of the newest. This tiny project was very instructive to the team in its results. A 3D print is not as irreplaceable as an archaeological artefact. In the 3D Lab this led very quickly to the insight by practical experience, that this tool from the Stone Age was designed and produced with a deep knowledge of design and ergonomics. These two projects of different complexity demonstrate again the potential of 3D technology in scientific and museum work.

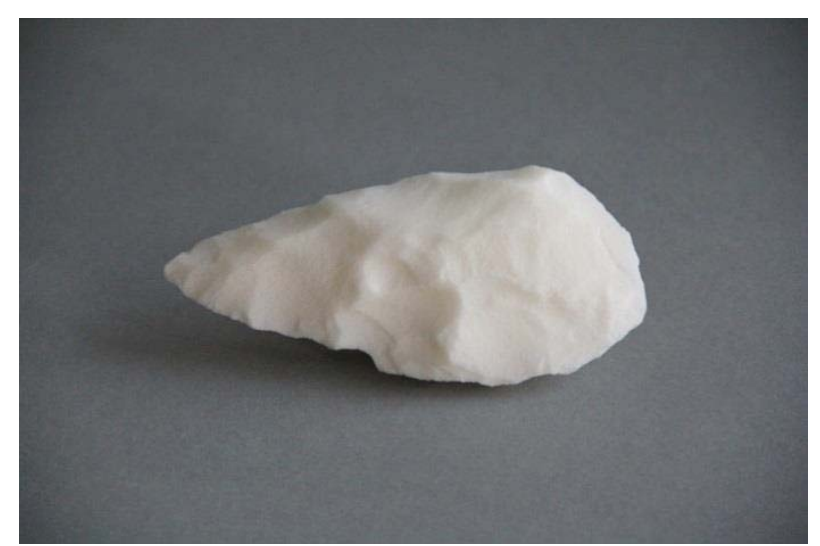

Figure 18: $3 D$ printed Upper Paleolithic biface found in Mauritania

\section{REFERENCES}

Helfrich, M. (ed.) (2012) Meisterwerke der Gipsformerei, Kunstmanufaktur der Staatlichen Museen zu Berlin. Hirmer-Verlag, Muenchen (in German).

Maaz, B. (ed.) (2006) Nationalgalerie Berlin, Bestandskatalog der Skulpturen. Seemann-Verlag, Leipzig (in German).

Schroeder, N. and Winkler-Horacek, L. (eds.) (2012) ...von gestern bis morgen... Zur Geschichte der Berliner Gipsabguss-Sammlung(en). Verlag Marie Leidorf, Rahden (in German).

Gößwald, U. (ed.) (2010) 99 x Neukölln. Museum Neukölln, Berlin (in German).

http://www.museum-neukoelln.de/ausstellungen99-neukoelln.php (retrieved 20 March 2014).

Schilling, R., Jastram, B., Wings, O., SchwarzWings, D., and Issever, A. (2013) Reviving the dinosaur: Virtual reconstruction and three dimensional printing of a dinosaur vertebra, Radiology, 270(3), pp. 864-871.

Reichhardt, H. J., Schäche, W. (eds.) (2008) Von Berlin nach Germania. Über die Zerstörung der "Reichshauptstadt" durch Albert Speers Neugestaltungen, 11. reprint, Verlag Transit, Berlin (in German).

Schäche, W. (ed.) (1991) Architektur und Städtebau in Berlin zwischen 1933-1945, Verlag Mann (Gebr.), Berlin (in German). 